\title{
Ser avó na família contemporânea: que jeito é esse?
}

\author{
Andreia Ribeiro Cardoso - Universidade Veiga de Almeida, Rio de Janeiro, Brasil \\ Leila Maria Torraca de Brito - Universidade do Estado do Rio de Janeiro, Rio de Janeiro, Brasil
}

\begin{abstract}
Resumo
O artigo apresenta pesquisa realizada com avós que cuidam de netos, discutindo temáticas como as modificações na família contemporânea, as relações intergeracionais e certas atribuições das avós nos tempos atuais. O objetivo principal da investigação foi compreender, por meio de grupos focais, como avós que tomam conta dos netos para que os pais trabalhem fora lidam com os encargos relativos ao cuidado das crianças. Foram organizados dois grupos, que reuniram doze participantes. A cada grupo foram oferecidas quatro reuniões de uma hora e trinta minutos. Constatou-se que nesse cenário as avós ocupam lugar central na vida de suas famílias, participando ativamente do cotidiano dos netos, proporcionando apoio afetivo e, por vezes, financeiro. Ao final do estudo destaca-se que o lugar social das avós como cuidadoras de seus netos expressa mudanças na configuração do grupo doméstico, quando a família extensa pode ser entendida como uma forma de organização na atualidade.

Palavras-chave: Relacionamentos entre avós e netos; Família contemporânea; Relações intergeracionais.
\end{abstract}

Being a grandmother in contemporary family: which way is that?

\begin{abstract}
The article presents research conducted with grandmothers who care for grandchildren, discussing topics such as changes in the contemporary family, intergenerational relations and certain assignments of grandmothers nowadays. The main objective of this research was to understand, through focused groups, such grandmothers taking care of grandchildren, for parents to work out, dealing with this charges. Two groups were organized which brought together twelve members. For each group were offered four meetings of one hour an thirty minutes. It was found that in this scenario grandmothers occupy a central place in the lives of their families, participating actively in the daily lives of their grandchildren, providing emotional support and sometimes financial help. At the end of the study it highlights that social role of grandmothers as caregivers of their grandchildren, expressed changes in the home group, when the extended family can be understood as a form of organization in the present. Keywords: Relationships between grandmothers and grandchildren; Contemporary family; Intergenerational relationships.
\end{abstract}

Ser una abuela en la familia contemporánea: ¿qué camino es ése?

\section{Resumen}

El artículo presenta una investigación realizada con las abuelas que cuidan a los nietos, discutiendo temas tales como los cambios en la familia contemporánea, las relaciones intergeneracionales y ciertas asignaciones de abuelas hoy en día. El objetivo principal de la investigación era comprender, a través de grupos focales, como las abuelas que cuidan de los nietos para que los padres trabajen fuera hacen frente a los cargos relacionados con el cuidado de los niños. Se realizaron dos grupos, que reunieron doce participantes. A cada grupo fueran ofrecidas cuatro reuniones de una hora y treinta minutos. Se encontró que en este escenario las abuelas ocupan un lugar central en la vida de sus familias, participando activamente de lo cotidiano de sus nietos, proporcionando apoyo emocional y a veces financiero. Al final el estudio destaca que el papel social de las abuelas como cuidadoras de sus nietos muestra cambios en el grupo doméstico, cuando la familia extensa se puede entender como una forma de organización en la actualidad.

Palabras-clave: Relaciones entre abuelas y nietos; Familia contemporánea; Relaciones intergeneracionales.

\section{Introdução}

O artigo visa apresentar os resultados obtidos em pesquisa de campo realizada com avós que cuidam de seus netos. O objetivo geral da investigação foi o de compreender, por meio de grupos focais, como avós que tomam conta de netos para que os pais trabalhem fora lidam com as responsabilidades relativas ao cuidado $^{1}$ das crianças. $\mathrm{Na}$ realização deste estudo, de

\footnotetext{
${ }^{1}$ No texto em questão optou-se por utilizar o termo cuidar como atividades/atribuições desempenhadas frequentemente pelos avós para com os netos, dentre elas: levar para escola, fazer companhia, administrar alimentação, banho, higiene, estudos, sono etc.
}

cunho qualitativo, também foi possível averiguar como as avós entendem essa tarefa e como são partilhadas, entre pais e avós, as atribuições com as crianças. Buscou-se verificar, ainda, qual a repercussão dessas tarefas na vida das avós. Os resultados obtidos nos "Grupos de encontros com avós", denominação que se atribuiu aos grupos efetuados, foram avaliados por meio de análise de conteúdo (Bardin, 1979; Minayo, 2003).

O intuito do uso dos grupos como ferramenta de pesquisa foi o de propor uma situação de interação entre avós, criando-se um foco de discussão e empregando-se o debate como principal meio para a troca de ideias e exposição de sentimentos. De acordo com Cruz Neto, Moreira e Sucena (2002), esta técnica tem 
por finalidade obter a "fala em debate" (p. 6), quando vários pontos são discutidos entre os participantes do grupo, que expõem conceitos, impressões e concepções sobre determinado tema.

No percurso do trabalho de campo foi possível aprofundar o conhecimento sobre alguns pontos específicos discutidos no referencial teórico estudado ao longo da pesquisa, obter novas informações sobre a temática e avaliar a pertinência, ou não, do emprego desses grupos com um espaço de profícuas reflexões.

Bleger (1998) argumenta que nas pesquisas por meio de grupos as pessoas podem abordar seus problemas e buscar soluções junto com os profissionais, de modo que a informação circule. $\mathrm{O}$ autor supõe que o grupo seja também um meio de aprendizagem, afirmando que esta se daria a partir das descobertas que se produzem no próprio grupo e da riqueza de experiências reveladas por cada participante.

\section{Avós no terceiro milênio}

As atribuições dos avós para com os netos nas sociedades ocidentais contemporâneas, como mostra a literatura sobre o tema (Coutrim, Boroto, Maia \& Vieira, 2006; Dias \& Silva, 1999; Lins de Barros, 1987; Lopes, Neri e Park, 2006; Segalen, 1996), passaram a ser bastante diversificadas, trazendo exigências e consequências distintas tanto para os primeiros como para as crianças. Percebe-se, por exemplo, que no século XXI, há aqueles que são cuidadores integrais dos netos, os que se responsabilizam por apenas um período do dia, os que veem os netos nos finais de semana e aqueles que os encontram eventualmente. No estudo que se empreendeu por meio dos grupos, optou-se por privilegiar avós que se ocupavam dos netos o dia todo ou, sistematicamente, por um período durante a semana.

No atual contexto de relações familiares, alguns pais e mães, diante de responsabilidades referentes ao cuidado dos filhos, encontram sérias dificuldades para conciliar as atribuições profissionais, pessoais e parentais. Dessa forma, muitas vezes são os avós que participam efetivamente da criação dos netos para que mãe e pai possam desempenhar suas funções profissionais, situação já assinalada por alguns autores, como Attias-Donfut e Segalen (2001), Billé (2002), Lins de Barros (2005); Coutrim, Boroto, Maia \& Vieira (2007) e Peixoto (2004). São tempos em que os avós, alguns já aposentados e estabilizados financeiramente, se apresentam com mais disponibilidade para cuidar das crianças do que propriamente os pais. Em virtude disso, muitos acabam por exercer o apoio afetivo e moral, bem como o suporte financeiro para seus netos.

A representação de avó, comumente descrita na literatura infantil e nos comerciais de televisão veiculados no Brasil é a de pessoas idosas, disponíveis para os netos. Nas histórias infantis, nota-se a grande diferença de idade entre avós e netos. No entanto, os dados estatísticos e os estudos de alguns autores (Attias-Donfut \& Segalen, 2001; Lopes, Neri e Park, 2005; Oliveira, 1999; Segalen, 1996) vêm mostrando que, na atualidade, tanto há avós com idade avançada como existem aqueles considerados muito jovens para esse papel. No contexto brasileiro, os avós jovens muitas vezes ainda estão inseridos no mercado de trabalho e, nesses casos, não conseguem cuidar dos netos. Mas, nos estudos desenvolvidos por Silva e Salomão (2003) com mães adolescentes, foi observado que, nessas situações, as avós acabam incorporando o papel de mães na relação com os netos, o que contribui para alavancar conflitos entre mãe e avó.

As tarefas executadas por avós no cuidado das crianças, aliadas ao forte vínculo da relação e à necessidade dos pais em repassar ou dividir a criação dos filhos, podem contribuir para que se consolide na família certa confusão de papéis (Attias Donfut e Segalen, 2001; Coutrim, Broto, Maia e Vieira, 2006). As avós, nessas situações, muitas vezes acabam assumindo as responsabilidades referentes aos pais e tomam para si todos os cuidados com as crianças. Nesse sentido, essa configuração que vai sendo tecida pode não ser percebida pelos membros da família. Como admite Billé (2002), aos avós é designado um papel muito sutil: ser capaz de fazer pelos netos sem, no entanto, usurpar a função dos pais; estar disponível, porém não atrapalhar; responder às demandas por conselhos, mas sem julgar; não se envolver nos projetos educativos, mas oferecer escolhas sem confrontar os genitores.

\section{Método}

Como já explicitado, na pesquisa em questão foram realizados dois grupos focais denominados "Grupos de encontros com avós". O grupo focal, em seu caráter subjetivo de investigação, é utilizado como estratégia metodológica qualitativa, conforme informação de Debus (1997).

Com cada grupo foram realizadas quatro reuniões que aconteciam uma vez por semana, com tempo previsto de uma hora e trinta minutos cada. No entanto, a duração das reuniões foi um pouco maior do que o 
previsto, em razão das discussões acaloradas das participantes sobre os temas abordados. A condução dos grupos coube a uma pesquisadora e a uma auxiliar de pesquisa, encarregada dos registros das reuniões.

\section{Participantes}

$\mathrm{Na}$ composição final dos grupos, reuniram-se cinco avós no primeiro e, no segundo, sete. Todas as integrantes dos grupos cuidavam sistematicamente de netos para que os pais das crianças pudessem exercer atividades laborativas. Essas avós possuíam recursos financeiros suficientes para a própria manutenção e se identificavam como pertencentes à classe média.

As participantes dos grupos tinham ciência sobre a pesquisa que se estava realizando e concordaram com a assinatura do termo de consentimento livre e esclarecido. Destaca-se que algumas avós não compareceram a um ou mais encontros, apresentando como justificativa para suas faltas a doença dos netos e/ou viagens.

\section{Instrumentos}

Para cada reunião foi previamente definido o tema a ser discutido, bem como as dinâmicas e os recursos utilizados como trechos de filmes, de músicas e textos. Tais instrumentos foram empregados com o intuito de contemplar questões que favorecessem o levantamento de informações necessárias aos objetivos propostos, como indicam Cruz Neto, Moreira e Sucena (2002) na referência à condução de grupos operativos. Foi prevista, também, a possibilidade de o planejamento ser alterado, em função de acontecimentos apresentados nas reuniões, o que efetivamente ocorreu nos dois grupos. Cada grupo, espontaneamente, por vezes direcionava as discussões para outros assuntos, de acordo com a interpretação que fazia das temáticas motivadoras da reflexão.

Os registros dos debates ocorreram de duas formas: por meio de gravação (gravador de voz) e de anotações das falas no decorrer dos encontros, o que incluía as narrativas e a linguagem não verbal (posturas, expressão e silêncios, por exemplo). Todas as impressões sobre o desenrolar de cada encontro foram detalhadas em diário de campo logo após os mesmos, quando as profissionais debatiam a respeito das informações e percepções sobre a reunião que ocorrera.

Conforme apontado por Minayo (2003), o diário de campo pode ser um instrumento de uso sistemático de suma importância, no qual devem ser anotadas as percepções, angústias, questionamentos e informações que não são obtidos por meio de outras técnicas utilizadas na pesquisa. As anotações do diário foram de grande valia para as fases de descrição e análise dos dados.

\section{Procedimentos}

Para a realização dos "Grupos de encontro com avós" foi elaborada uma série de ações próprias de pesquisas com grupos no que diz respeito à abordagem dos candidatos, à divulgação do trabalho, à escolha das participantes, à preparação dos encontros e à escolha do material de apoio a ser utilizado. Os grupos ocorreram nas dependências de duas instituições distintas: uma escola e um clube esportivo, nas cidades do Rio de Janeiro e de Niterói, respectivamente. A escolha dos locais aconteceu em função de serem estabelecimentos onde as avós geralmente levavam os netos.

O convite para aqueles que desejassem participar dos grupos foi divulgado nos dois estabelecimentos de forma distinta. No grupo realizado na escola foram enviados bilhetes pelas agendas dos alunos; já naquele que ocorreu nas dependências de um clube esportivo, a divulgação foi por meio de cartazes fixados na respectiva associação. Como resposta aos convites, 19 avós, do sexo feminino, revelaram interesse em participar da pesquisa.

Após o término do prazo de inscrição, que poderia ser por e-mail ou por telefone, foram agendadas entrevistas iniciais com as candidatas. $\mathrm{O}$ objetivo dessas entrevistas era basicamente o de ouvir individualmente as avós, com o propósito de averiguar se as mesmas cuidavam sistematicamente de netos para os pais das crianças trabalharem fora. A ausência desse requisito resultava na impossibilidade de participação na pesquisa.

\section{Analise de dados}

De acordo com Bardin (1979), a análise de resultados de uma pesquisa envolve um processo sistemático de busca e de organização que tem como meta o entendimento do conteúdo obtido. $\mathrm{O}$ trabalho de análise do conteúdo deve ser previsto e coerente com a forma de coleta de dados. Durante o processo de análise, as etapas de "leitura flutuante", definição de unidades de registro e recorte, demarcação de núcleos de sentido, identificação das categorias e análise interpretativa dos dados fizeram parte do processo de construção dos resultados.

Nesta pesquisa, para a análise dos dados foram utilizados: as anotações das entrevistas individuais realizadas pela pesquisadora; as informações registradas 
na ficha de identificação preenchida no momento da entrevista; as anotações dos encontros realizadas pela pesquisadora auxiliar; as impressões registradas no diário de campo após cada encontro e a escuta das gravações. Ao compilar esses dados, foi possível identificar significados e temas recorrentes nas falas das participantes e selecionar trechos que os representassem.

As informações obtidas foram reunidas em categorias relativas à problemática da pesquisa e aos dados brutos (significados comuns das falas dos entrevistados). As partes significativas foram agrupadas em temas ou perspectivas de investigação, escolhidas a partir de categorias de análises concernentes ao referencial teórico.

\section{Resultados e Discussão}

Nos debates que ocorreram nas distintas reuniões dos grupos, as avós abordaram não só o papel que exercem junto aos netos, como também outras atividades e atribuições que estão relacionadas ao fato de cuidarem das crianças. Assim, na análise dos resultados foram estabelecidas as seguintes categorias: o que é ser avó; relacionamentos entre avós e netos, cuidar dos netos; ajuda que prestam aos filhos; limites aos filhos e netos. Para fins deste artigo serão apresentados, em conjunto, resultados referentes às três primeiras categorias.

Ao discutirem o que entendem sobre o significado de ser avó, algumas participantes declararam que é melhor do que ser mãe, pois a avó é mais experiente e consegue lidar com os problemas familiares com sabedoria, principalmente no que diz respeito às questões relacionadas aos netos. Foi consenso entre as participantes o fato de acreditarem que o papel de avó traz à cena o comprometimento nessa tarefa de cuidar das crianças, referindo-se ao amor incondicional aos netos e ao prazer, alegria e gratificação que obtinham.

Como igualmente constatado por Attias-Donfut e Segalen (2001), os avós são considerados pessoas importantes para apoiar a família em diversos contextos como: dificuldades financeiras, divórcio, gravidez, ou mesmo na ausência dos pais. Nesse aspecto, é possível citar a ponderação feita por Turquesa ${ }^{2}$, integrante de um dos grupos, ao considerar a participação dos avós como fundamental na formação psíquica dos netos.

Certas avós dos grupos realizados classificaram suas vivências como de intensa afetividade com os netos. Reconheciam também que, além de ajudarem

\footnotetext{
${ }^{2}$ Nome fictício
}

as crianças, já receberam muita contribuição destas. Nessas situações, os netos, considerados como fiéis companheiros e verdadeiros salvadores, auxiliaram as avós em inúmeros momentos de dificuldades. Outras participantes, todavia, contestaram esse comentário e justificaram que os netos, por serem crianças, não devem ter a responsabilidade de ajudar as avós a superarem seus problemas. Nessa discussão, sentimentos como obrigação, prazer ou uma mistura dos dois foram apresentados diante da tarefa de cuidar dos pequenos.

Verificou-se na literatura estudada (Lins de Barros, 1987; Peixoto, 2004; Sampaio, 2008; Segalen, 1996) que, em razão da grande complexidade no desempenho do papel de avós, boa parte daquelas que cuidam de netos adota a postura que se espera dos pais das crianças; outras, no entanto, só querem desempenhar o papel de avós. Todavia, há também aquelas que, ao rejeitarem o papel de cuidadoras, se distanciam dos netos, convivendo com as crianças apenas em situações esporádicas. Nessa discussão, as participantes da pesquisa também informaram que conheciam muitas avós que se negavam a interagir com os netos, porque não queriam ser consideradas idosas. Questiona-se, portanto, o referencial simbólico que o papel de avó traz em nossa sociedade. Ser avó é ser velha?

$\mathrm{Na}$ discussão sobre o papel das avós, constatou-se a dificuldade que a maioria das participantes teve em diferenciar o que é ser avó do papel que desempenhavam como cuidadoras dos netos. Algumas até arriscaram falar das brincadeiras e da relação que mantinham com outros netos dos quais não cuidavam, mas, nesses comentários, acabavam trazendo situações que vivenciavam com aqueles dos quais elas acompanhavam o cotidiano. Nesse âmbito, Attias-Donfut e Segalen (2001) revelam que não há modelos nem regras específicas para ser avó. A participação no cuidado dos netos é uma relação voluntária, a ser negociada entre os envolvidos.

A única bisavó participante dos "Grupos de encontros com as avós" não conseguiu distinguir se há diferenças entre ser avó e ser bisavó. Ela apenas destacou a longevidade, o prazer e os sentimentos de alegria como característicos das bisavós. Mas, no que se refere aos papéis desempenhados pela mãe e pela bisavó, esta assinalou que deve haver limites entre os dois, cabendo à bisa ajudar quando for preciso e respeitar as limitações de seu papel.

Interessante foi verificar o quanto a presença da bisavó em um dos grupos ajudou a destacar, nas discussões, temáticas relacionadas à sabedoria e à experiência 
das avós. Em alguns momentos, quando as participantes reclamavam da falta de tempo para realizar atividades pessoais ou mesmo da dificuldade em lidar com os cuidados dos netos, logo se lembravam do relato da bisavó, que mostrava, com sua experiência e seu bom humor, o quanto é possível cuidar das crianças sem que essa tarefa inviabilize os projetos pessoais.

Nos estudos com bisavós apresentados por Dias e Pinto (2007), essas pouco se diferenciavam dos papéis assumidos por avós, a não ser no que diz respeito a dificuldades referentes a certas limitações físicas decorrentes da idade. As autoras apontaram que já é uma tendência das famílias contemporâneas o relacionamento entre quatro gerações, embora ainda sejam escassos os estudos que abordem esse aspecto.

Nos relatos e interações no grupo, as participantes declararam que se sentiam com mais atribuições de mãe do que propriamente de avó. Justificaram ser esse o motivo pelo qual ficavam insatisfeitas, pois achavam que estavam perdendo oportunidade de realizar algo diferente para os netos. Elas expressaram que, ao mesmo tempo em que se sentiam próximas das crianças, não conseguiam se relacionar como de fato entendiam que seria o papel de avós. Destacaram que, ao cuidar dos netos, vivenciavam o "lado de mãe" das crianças deixando, nesses momentos, de exercer o papel que gostariam: o de avós. Esse parece ser o incômodo que sentem aquelas que cuidam dos netos.

Algumas relataram que assumiram a responsabilidade pelo cotidiano das crianças, cuidando delas integralmente, todos os dias da semana. Muitas vezes se incumbiam de todas as tarefas justamente porque as mães das crianças não tinham tempo ou, por algum outro motivo, não podiam fazê-lo. As participantes se consideravam "mães substitutas", algumas, inclusive, pelo fato de seus netos residirem com elas.

Discutindo a questão, duas participantes disseram: "Não gostaria de ter responsabilidade de mãe. Só queria ser avó para passear e 'estragar' [o neto]"; "Gostaria de ser avó com mais leveza. Minha relação com os netos deveria ter menos responsabilidades e mais brincadeiras".

Mas, outras vezes, parece que as avós desejam permanecer nesse lugar de cuidadoras. Algumas informaram que partiu delas a oferta para se responsabilizar pelas crianças, quando perceberam ser esta a dificuldade dos pais para assumir plenamente as atividades profissionais. Outras, mesmo afirmando veementemente que estavam cuidando dos netos por imposição, expressavam contentamento quando, nos encontros, trocavam informações sobre o dia a dia e o próprio desenvolvimento das crianças.

Ainda que questionassem esse lugar de cuidadoras, poucas avós tentaram mostrar aos pais das crianças que eles deveriam se responsabilizar pela tarefa de cuidar dos filhos. Entre elas estava a bisavó de 84 anos, que explicou à neta que não poderia cuidar dos bisnetos todos os dias da semana, porque não queria abrir mão de atividades pessoais como aulas de dança, viagens, participação em grupo de terceira idade e hidroginástica. Essa senhora, na tentativa de ajudar a neta, dividia com a avó paterna dos pequenos os cuidados dos bisnetos, ficando as crianças três dias da semana com uma e dois dias com a outra. A bisavó referiu-se a essa solução como a mais adequada para todos, mesmo sabendo que a vontade da neta era de que os filhos fossem cuidados exclusivamente por ela (bisavó), visto que a própria participante teve essa atribuição com a neta.

Situação distinta foi mencionada por uma participante que, nos encontros, reclamou que assumia todas as tarefas com relação aos netos. Confessou que, no relacionamento com o filho e a nora, não conseguia impor limites e acabava se incumbindo de todos os cuidados relativos às crianças. Essa avó compreendia que a dificuldade era sua, declarando que admirava outras do grupo que procediam de forma diferente na relação com os pais dos netos. Entretanto, acabou justificando seu comportamento pela falta de tempo dos pais das crianças, dizendo que não havia nada o que fazer para alterar a situação, já que os pais estudavam e trabalhavam muito.

Nesses e em outros casos, as participantes disseram que sentiam pena das filhas ou porque trabalhavam muito, ou pelo fato de serem separadas, ou simplesmente pela falta de tempo dessas para cuidarem dos próprios filhos. A partir desses relatos, percebe-se uma forte solidariedade intergeracional nos relacionamentos entre mães e filhas, de modo que as últimas possam se desenvolver profissionalmente, como afirmam alguns autores (Attias-Donfut, 2004; Attias-Donfut e Segalen, 2001; Peixoto e Luz, 2007; Rocha-Coutinho, 1998). Na visão de Moragas (2004), a cooperação entre pais e avós geralmente é voluntária e benéfica, porém, enquanto é considerada vantajosa para os pais pela possibilidade de cumprirem seus compromissos profissionais, pode resultar em obrigação para os avós, que, com essas atividades, sentem um esgotamento físico e mental.

Foi possível perceber que, na história das participantes dos grupos, algumas vivenciaram situações semelhantes às que os filhos hoje atravessam. Essas 
avós também foram mães que trabalharam fora e deixaram os filhos tanto com empregadas como com o marido, ou mesmo com as avós das crianças. Esse dado foi motivo de muita reflexão nos encontros. Algumas acreditavam que faziam pelos netos independentemente de terem feito, ou não, pelos filhos; outras admitiram que não vivenciaram o suficiente sua maternidade e que se dedicavam ao papel de avós como uma forma de compensar o que deixaram de fazer pelos filhos.

Uma participante, por exemplo, disse que, no passado, não se sentia disponível para os filhos como se sente atualmente para as netas. No seu caso, explicou que, quando os filhos eram pequenos, estava muito envolvida no trabalho e não pôde se dedicar ao desenvolvimento desses, que ficaram a cargo da empregada e do próprio marido, que, na época, tinha mais disponibilidade para as crianças. $\mathrm{O}$ mesmo verificou-se no relato de outras participantes dos grupos. Esse dado também foi corroborado por outros estudos realizados (Attias-Donfut e Segalen, 2001; Coutrim, Broto, Maia e Vieira, 2006), quando foi constatada a vontade de os avós se dedicarem aos netos por acharem que fizeram pouco pelos filhos, quando estes eram pequenos.

Outras participantes, porém, quando questionadas sobre como seria a tarefa de cuidar dos netos, disseram que repetem o que fizeram com os filhos, de modo a mostrar a referência e a experiência bem-sucedida. Uma delas disse: "adoro contar histórias e passear com meus netos, da mesma forma que fiz com os meus filhos".

Nessa discussão, portanto, com frequência mencionaram que, ao cuidar dos netos, lembravam-se do exercício de sua maternidade. Uma delas recordou que, na época, combinou com o marido que ela ficaria em casa cuidando dos filhos. Declarou que essa foi uma opção familiar e que: "hoje eu poderia ser uma mulher realizada profissionalmente, mas acho que a minha escolha foi a mais acertada. Estou satisfeita com a forma como cuidei de meus filhos e a que atualmente faço com os netos".

Para as que tomaram essa decisão, todo o sacrifício no cuidado com as crianças valeu a pena, por isso, consideravam importante "se doar" na tarefa de cuidar dos netos. Mais uma vez constata-se que certas avós acabam mesclando seu papel com o de mãe, não conseguindo diferenciar as atribuições que tiveram para com os filhos das que lhes caberiam com os netos. Esse dado também foi apontado nos estudos realizados por Peixoto e Luz (2007).

Ressalta-se ainda que, ao falarem do passado, algumas participantes dos grupos informaram que não conheceram seus avós, portanto, não possuíam parâmetros para exercer esse papel, como também constataram Kipper e Lopes (2006) em pesquisa que realizaram. Como a expectativa de vida no passado era bem menor, não havia muitas famílias com três gerações convivendo. Nesse sentido, Attias-Donfut e Segalen (2001) consideram que se vivencia um momento único no que diz respeito ao papel de avós. Outras avós dos grupos planejavam dar continuidade à tarefa de cuidar de crianças, agora com outros netos ou bisnetos, mostrando a vontade de permanecer nesse papel. Nessa situação, pode ser pertinente indagar: o que desejam as avós ao declararem a vontade de estender a tarefa de cuidar dos netos para os outros que virão? Duas participantes disseram que se sentem sós e gostariam de ter outros netos para cuidar. Dessa maneira, talvez, uma das respostas à pergunta seja: cuidar dos netos pode significar uma forma de se sentirem úteis ou de preencher o vazio que sentem. Isso se confirma no caso de uma senhora, que narrou sobre sua solidão, concluindo que gostaria mesmo é de ter um namorado, ao invés de preencher seu tempo com a tarefa de cuidar dos netos. Portanto, para as participantes, essa incumbência traz mudanças ao cotidiano pouco ativo e, assim, contribui para a luta contra o envelhecimento. Notou-se que tal relato se coaduna com o que Sampaio (2008) esclarece em seu texto a respeito de que esta seria mais do que uma ajuda pontual aos pais das crianças, pois ela está carregada de afetividade e de interesses pessoais.

Outro aspecto importante a ser analisado é a percepção das avós diante do comportamento dos netos. As participantes concordaram que os netos se portavam de maneira diferenciada com elas e com os pais. Interpretaram que aquelas crianças que ficam muito tempo sem contato com os pais sentem falta destes e, quando estão próximos, tentam interagir por meio de brincadeiras, solicitando atenção e carinho dos mesmos. Por esse motivo, eram favoráveis a que os netos tivessem o máximo de contato com seus pais e preferiam se ocupar de toda a rotina que envolvia dar banho, alimentar, trocar a roupa e tudo o que fosse necessário para que os pais se dedicassem apenas a brincar com as crianças. Está explícita nessa atitude a vontade das avós de poupar seus filhos do papel de cuidadores, justificando que, além de chegarem cansados, precisavam brincar com os filhos. Percebe-se, então, nessas situações, uma inversão de papéis entre avós e pais. Parece que, nesses casos, as avós que assim procedem se identificam tanto com o papel de cuidadoras que preferem conceder aos pais das 
crianças apenas os momentos de brincadeira - o que seria papel de avós, como algumas disseram.

Nesse aspecto, foi interessante observar o quanto o tema "brincadeiras com os netos" mostrou a ambiguidade dos papéis vivenciados pelas avós. Enquanto cuidadoras, elas outorgavam as brincadeiras com as crianças aos pais; no entanto, nas discussões em grupo, verbalizaram que é pelas diversões com os netos que vivenciavam o verdadeiro papel de avós, resgatando juventude e disposição.

No que diz respeito ao tema cuidar dos netos, se compreendeu neste trabalho com grupos que, por meio das discussões, oposições e discordâncias por parte de algumas participantes, as avós perceberam as diferenças, o interesse e os motivos que conduziam cada uma a essa tarefa com as crianças. Assim, no debate houve consenso de que se deve procurar fazer o que se gosta e o que se pode no que concerne ao relacionamento com as crianças, levando-se sempre em consideração os limites necessários para conciliar desenvolvimento pessoal e bom relacionamento familiar. De acordo com Lins de Barros (2003, 2005), é por intermédio desse contato com os netos que as histórias de família, a cultura e o conhecimento dos mais velhos podem ser transmitidos às futuras gerações, permitindo aos avós ficarem como os perpetuadores da cultura na família o que contribui para destacar a importância das relações intergeracionais.

Attias-Donfut e Segalen (2001), analisando as relações familiares na França, explicam que há algumas décadas os avós não eram tão inseridos no contexto familiar dos filhos e dos netos, dado que vem se modificando, a ponto de se ter hoje uma geração de avós que pode desfrutar da relação com os netos e vê-los crescer, em média, até os vinte anos de idade. As autoras também alertam para o fato de que, na França, pela redução da taxa de natalidade, as pessoas cada vez têm menor número de netos. Nesse aspecto, concorda-se com Segalen (1996) no questionamento a respeito de como será a relação entre avós, pais e netos nos próximos anos, uma vez que menos filhos e netos terão que se ocupar de um maior número de pessoas idosas na família.

\section{Considerações finais}

Os dados apurados nos grupos trouxeram algumas reflexões sobre as vivências de avós que cuidam de netos. Foram destacadas certas especificidades do que seria o papel de avós para as participantes e as dificuldades de, nos dias atuais, se encontrar uma definição sobre o que é ser avó. Outros estudos (Attias-Donfut e Segalen, 2001) também corroboram tal questão, informando que não há um modelo exato, nem regras precisas do ser avós. As tarefas direcionadas a estas vão sendo combinadas e construídas entre os envolvidos. Diante de tal interpretação, percebe-se que é o contexto específico e a disponibilidade de cada membro na família que vão permear as relações entre avós e netos. Outros autores também associaram o papel que os avós desempenham com a aquisição de valores e o modo de vida dos netos (Billé, 2002; Dias \& Silva, 1999).

Durante os encontros da pesquisa que se realizou, as participantes foram unânimes em alguns pontos, discordando em outros, mostrando o quanto as vivências de avós e de mães se mesclam quando cuidam dos netos. Nessa discussão, foi consenso entre elas o fato de aflorarem muitos sentimentos quando estão desempenhando este papel. Em alguns momentos, as avós justificaram a importância dos netos em suas vidas e também encontraram meios para explicar a ajuda que prestam a eles. Verificou-se, dessa forma, tanto a reciprocidade nas relações entre avós e netos para que as transmissões intergeracionais se constituam como referências para a reprodução familiar como o fato desse cuidado preencher carências de idosos.

Os relatos apresentados pelas participantes expressam mudanças nas configurações do grupo doméstico, onde a família extensa vem se constituindo como um dos modelos da atualidade, por diversos motivos, como o desemprego e o divórcio. O lugar social de cuidadoras situa as avós em papéis voltados para educação e socialização dos netos. A análise dos grupos de encontro com avós sugere que se podem compreender os discursos das avós a partir de práticas sociais destinadas a essa geração. Os diferentes significados e sentidos que apareceram nos grupos estudados apontam para a pertinência de se pensar as relações entre avós e netos a partir das experiências familiares vivenciadas no contexto contemporâneo.

Como analisado na literatura estudada (Bauer e Gaskell, 2002; Bleger, 1998; Morgan,1997), também se verificou na pesquisa em questão que os grupos focais auxiliam na compreensão das relações sociais, ajudando as participantes a expressarem suas opiniões e a buscarem algumas soluções a partir da circulação de informações que ocorre nos encontros. Esse dado pode ser exemplificado no relato de uma participante: "eu não pensava que fosse aprender tanto, de forma simples e com quem vive as mesmas situações que eu passo. 
Isso é fantástico!". Dessa maneira, o trabalho com grupos possibilitou não só a produção de conhecimentos, como parece ter colaborado para algumas decisões e reflexões das participantes.

\section{Referências}

Attias-Donfut, C. (2004). Sexo e envelhecimento. Em: C. E. Peixoto (Org.). Família e envelhecimento. (pp. 85-108). Rio de Janeiro: FGV (Coleção família, geração e cultura).

Attias-Donfut, C, \& Segalen, M. (2001). Le invention de la grand-parentalité. Em: D. Gall \& Y. Bettahar. La pluriparentalité. (pp. 243-260), Paris: Universitaires de France.

Bardin, L. (1979). Análise de conteúdo, Lisboa: Edições 70.

Bauer, M. W., \& Gaskell, G. (2002). Pesquisa qualitativa com texto, imagem e som: um manual prático. Petrópolis, RJ: Vozes.

Billé, M. (2002). A quoi servent les grands-parents? Des grands-parents pour intro-duire au "sacré". Dialogue - Recherches cliniques et sociologiques sur le couple et la famille, $4^{\circ}$ trim., 3-10.

Bleger, J. (1998). Temas de psicologia: entrevista e grupos. (2a ed.). São Paulo: Martins Fontes.

Boff, L. (1999). Saber cuidar. Ética do bumano: compaixão pela terra. Petrópolis, RJ: Vozes.

Coutrim, R. M. E., Broto, I. G., Maia, I. O., \& Vieira, L. C. (2006). Apontamentos a respeito do papel dos avós no cotidiano escolar de crianças do ensino fundamental. Em IV Encontro de Pesquisa em Educação da UFPI -GT-16. Disponível em: http://www. ufpi.edu.br/subsiteFiles/ppged/arquivos/files/ eventos/2006.gt16/GT16_2006_04.PDF.

Coutrim, R. M. E., Broto, I. G., Maia, I. O., \& Vieira, L. C. (2007). O que os avós ensinam aos netos? A influência da relação intergeracional na educação formal e informal. Em Congresso Brasileiro de Sociologia. Anais do Congresso Brasileiro de Sociologia, Recife, Pernambuco: UFPE, (pp. 1-15).

Cruz Neto, O., Moreira, M. R., \& Sucena, L. F. M. (2002). Grupos focais e pesquisa social qualitativa: o debate orientado como técnica de investigação. Trabalho apresentado no XIII Encontro da Associação Brasileira de Estudos Populacionais, Ouro Preto, MG, 26p. Disponível em: http://www.abep.nepo.
unicamp.br/docs/anais/pdf/2002/Com_JUV_ PO27_Neto_texto.pdf.

Debus, M. (1997). Manual para excelência en la investigacion mediante grupos focales. Washington, D.C.: Academy for Educational Development.

Dias, C. M. S. B., \& Silva, M. A. S. (1999). Os avós: uma revisão da literatura nas três últimas décadas. Em T. Féres-Carneiro (Coord.). Casal e familia: entre a tradição e a transformação. (pp. 118-149). Rio de Janeiro: NAU.

Dias, C. M. S. B., \& Pinto, V. C. (2007). A percepção dos bisavós sobre seu papel. Rev. Enferm UFPE [OnLine], 1(2), 198-203.

Kipper, C. D. R., \& Lopes, R. S. (2006). O tornar-se avó no processo de individuação. Psicologia: Teoria e Pesquisa, 22(1), 29-34, jan./abr.

Lins de Barros, M. L. (1987). Autoridade e afeto: avós, filhos e netos na sociedade brasileira. Rio de Janeiro: Jorge Zahar.

Lins de Barros, M. L. (2003). Reciprocidade e fluxos culturais entre gerações. Em: Congresso Internacional Co-Educação de Gerações. SP: São Paulo. Disponível em: http://www.sescsp.org.br/sesc/conferencias.

Lins de Barros, M. L. (2005). Memória, gênero e geração na sociedade brasileira contemporânea. Praia Vermelha: estudos de politica e teoria social, Rio de Janeiro: UFRJ, 13, 44-68.

Lopes, C., Neri, A. L., \& Park, M. B. (2005). Ser avós ou ser pais: os papéis dos avós na sociedade contemporânea. Textos sobre Envelhecimento, Rio de janeiro, 8(2). 239-253. Disponível em: http:// revista.unati.uerj.br/scielo.php? script $=$ sci_ arttext\&pid $=$ S1517- 59282005000200006\&lng $=\mathrm{p}$ t\&nrm $=$ iso.

Moragas, R. M. (2004). As relações intergeracionais nas sociedades contemporâneas. Revista A Terceira Idade. São Paulo, 15(29). 7-27, jan.

Oliveira, P. S. (1999). Vidas compartilhadas: cultura e co-educação de geraçôes na vida cotidiana. São Paulo: Hucitec; FAPESP.

Peixoto, C. E. (2000). Avós e netos na França e no Brasil: a individualização das transmissões afetivas e materiais. Em C. E. Peixoto, F. Singly \& V. Cicchelli (Orgs.). Família e individualização. (pp. 95-111), Rio de Janeiro: FGV.

Psico-USF, Bragança Paulista, v. 19, n. 3, p. 433-441, set./dez. 2014 
Peixoto, C. E. (2004). Aposentadoria: retorno ao trabalho e solidariedade familiar. Em C. E. Peixoto (Org.). Família e envelhecimento. (pp. 57-84), Rio de Janeiro: FGV, (Coleção Família, geração e cultura).

Peixoto, C. E., \& Luz, G. M. (2007). De uma morada à outra: processos de re-coabitação entre as gerações. Cadernos Pagu, 171-191, jul./dez.

Rocha-Coutinho, M. L. (1998). De Cinderela a mulher maravilha: a maternidade em tempos de mudança. Série Documenta. Rio de Janeiro, 6(9), 91-116.
Sampaio, D. (2008). A razãa dos avós. (3a ed.). Lisboa, Portugal: Caminho.

Segalen, M. (1996). Sociologia da família. Lisboa, Portugal: Terramar.

Silva, D. V., \& Salomão, N. M. R. (2003). A maternidade na perspectiva de mães adolescentes e avós maternas dos bebês. Estudos de Psicologia, 8(1), 135-145.

Recebido em: 06/05/2013

Reformulado em: $12 / 02 / 2014$

Segunda reformulação em: 12/03/0214

Aprovado em: 23/04/2014

Nota das autoras:

Agradecimentos: À Capes, pela bolsa de doutorado concedida à primeira autora quando realizou a pesquisa apresentada.

Sobre as autoras:

Andreia Ribeiro Cardoso é graduada em Psicologia (UFRJ), possui especialização em Psicologia Jurídica, mestrado e doutorado em Psicologia Social pela UERJ. Desenvolve atividades como professora dos cursos de Graduação em Psicologia e Direito na Universidade Veiga de Almeida (RJ). É psicóloga do Tribunal de Justiça do Estado do Rio de Janeiro e tem experiência nas áreas de Psicologia Clínica e Psicologia Jurídica.

Leila Maria Torraca de Brito é professora associada do Instituto de Psicologia da Universidade do Estado do Rio de Janeiro (UERJ), docente do Programa de Pós-Graduação em Psicologia Social da UERJ, mestre e doutora em Psicologia pela Pontifícia Universidade Católica do Rio de Janeiro e pós-doutora em Direito pela Universidade Federal do Paraná e pela Pontifícia Universidade Católica de Minas Gerais.

Contato com as autoras:

Universidade do Estado do Rio de Janeiro

Rua São Francisco Xavier, 524 - sala 10.001-B, Maracanã

CEP: 20550-900.

Rio de Janeiro-RJ. 
